УДК 316.6:159.953

\title{
ВИДЫ И ЭЛЕМЕНТЫ СОЦИАЛЬНОЙ ПАМЯТИ
}

\section{(C) 2013 г. Э. Г. Позднякова-Кирбятьева}

\section{Харьковский национальный педагогический университет им. Г. С. Сковороды}

В статье рассматриваются психологические виды памяти в соииальном плане. Анализируется виды памяти и содержание памяти. Выделяются функцииональные элементы. Рассматривается коммуникачия как важнейший механизм транслящии социально-исторической памяти. Рассмотрев предмет памяти через функииональные элементы, автор делает вывод, что эта сторона социальной памяти является внешней для её субъектов.

Ключевые слова: сочиильная память; память; функциональные элементы; виды памяти; социально-историческая память.

In the article the psychological types of memory are examined from the sociologic positions. The types of memory and the maintenance of memory are analyzed; its functional elements are shown. Communication is examined as major mechanism for the translation of social and historical memory. Considering the sense of memory basing on the idea of functional elements, author draws a conclusion, that this side of social memory is external for its subjects.

Key words: social memory; memory; functional elements; kinds of memory; social and historical memory.

Социальная память - это многофункциональное явление, выступающее в различных социальных контекстах и являющееся объектом различных наук.

Само словосочетание «социальная память» вводит исследователя в круг интересов нескольких дисциплинарных научных подходов: исторического, психологического и социологического.

Память является, как известно, общепсихологическим понятием, относясь к психическим процессам. Её определение установилось в такой форме: «запоминание, сохранение и последующее воспроизведение прошлого опыта». Иногда определение выглядит более пространным, с указанием того, что именно может составлять этот прошлый опыт.

Так, при классификации мнемических процессов в общей психологии используется разделение памяти на четыре вида в зависимости от особенностей материала запоминания и воспроизведения: двигательная память (различные движения и их системы); эмоци- ональная (аффективная) память - память на чувства; образная память - сохранение представлений, предоставленных анализаторами (органами чувств); словесно-логическая (вербальная) память [4]. Эти виды памяти, выделенные психологами, сохраняют свою видовую сущность и для социальной памяти. Рассмотрим эти психологические виды памяти в социальном плане.

Содержание памяти, ее материал представляет собой сложное образование, содержащее как статические, так и динамические компоненты, обусловленные двойственным характером социума: наличием в нем постоянных черт, инвариантов, обеспечивающих стабильную социальную идентичность нации, и динамических компонентов, обусловленных историей, развитием, модернизацией общества.

В плане психологических механизмов перечисление указанных видов памяти неявно подразумевает процесс перевода раздражителя в материал для сохранения. При всем многообразии происхождения - сигналы ощу- 
щений, мысли, догадки, фантазии - итогом является создание специфических образов, которые в приводимой тематике определяются как «представления памяти».

Для социального плана необходимо углубиться в понимание объекта с точки зрения теории деятельности. Можно утверждать, что первично «раздражителем», который станет «материалом» социальной памяти, оказывается событие, имеющее социальную значимость. Однако временной масштаб существования социумов предполагает, что первичный раздражитель настолько отдален в прошлом, что современные поколения (а тем более - будущие) не являются свидетелями первичного раздражителя, поэтому имеют дело уже с его последствиями - то ли с материальным свидетельством, то ли с образом или представлением, которое уже является атрибутом не индивидуальной, а именно социальной памяти.

То есть, объект в плане социальной памяти распадается на вполне «осязаемые» материальные носители сведений о первичном раздражителе, с одной стороны, а с другой представления о нем, которые как раз и хранятся в социальной памяти. Эти феномены также могут характеризоваться как первичная и вторичная память в соответствии с феноменологической теорией темпоральности Э. Гусснерля [1].

Таким образом, внутри объекта социальной памяти как деятельности разграничим собственно событие социальной жизни и то, что стало «материалом» социальной памяти. Далее, в материале необходимо разделить собственно материальный носитель и представленность «материала» в общественном сознании, для чего обозначим её термином «предмет социальной памяти». Именно этот предмет будем структурировать через функциональные элементы, дополнив затем рассмотрением материальных носителей памяти.

Необходимость выделения функциональных элементов вызвана многофункциональностью социальной памяти и необходимостью системной характеристики различных функций.

Следует отметить, что описание каждого из функциональных элементов может быть уточнено благодаря их аспектному структу- рированию. Они становятся в этом случае адекватным информационным базисом для анализа феноменов социальной памяти, причем удовлетворяя при этом методологическим требованиям всесторонности и полноты, а его использование позволяет не только упорядочить предмет рассмотрения, но и избежать перекосов или упущений.

Функциональные элементы анализируются путем всевозможных соотношений субъекта и объекта, что оказывается довольно существенным для рассмотрения предмета социальной памяти. Необходимо найти соответствия общепсихологическим видам памяти с функциональными элементами, что даст в итоге обобщенную структуру предмета социальной памяти.

Двигательная память соответствует преобразовательному функциональному элементу, который фиксирует роль социальной памяти в процессах социальных трансформаций, модернизаций и т. п.

В теории преобразовательная деятельность «направлена» от субъекта на объект, при этом приводит к изменениям существующего и созданию того, чего раньше не было. В зависимости от объекта она может быть преобразованием природы, общества, человека.

Всё это составляет содержание того, что сохраняется в социальной памяти, относясь к различным сторонам преобразования.

Рассматривая формальные уровни в групповом субъекте отметим, что всё это касается наиболее масштабного уровня - большой социальной группы - то есть, речь идет о явлениях, которые в социальной психологии называются «массовидные» (затрагивающие так или иначе каждого члена большой группы или её большинство).

На уровне конгломерата малых групп в плане предмета социальной памяти речь должна идти о достижениях фирмы, о материальной стороне её деятельности (ощутимое производство); о тех принципах работы, которые обязательны к запоминанию для использования в профессиональной деятельности.

На уровне малой группы это конкретизируется в ответ на вопрос «в чем состоит преобразовательная сторона работы персонала в этой малой группе», а прошлые достижения 
в материальном преобразовании фиксируются как образцы для дальнейшей деятельности персонала, выполняя, таким образом, мотивирующую или, точнее, стимулирующую функцию.

На уровне микрогруппы этот компонент наиболее обширный по своим проявлениям, ибо призван давать ответ на вопрос «что делать?» в разнообразнейших житейских ситуациях, которые непрерывно сменяют друг друга, а то и актуализируются совместно. Видно также и то, что на этот уровень оказывают влияние все вышестоящие уровни, поскольку они задают более общие контексты. По некоторым сторонам преобразования члены микрогруппы могут использовать тот прошлый опыт, который сложился у них «на работе». Таким образом, «семейные традиции» естественным образом лежат внутри «народных традиций», составляя их предметную часть.

В свою очередь эмоциональная (аффективная) память - память на чувства — coответствует чувственному функциональному элементу.

В теории деятельности он основывается на специфической форме отражения объекта субъектом. Ценность объекта устанавливается непосредственной реакцией субъекта (индивидуального или коллективного) в соответствии с тем, как входит объект в жизненный опыт этого субъекта, какое отношение к себе вызывает, как он эмоционально усваивается. Ценностно-ориентационная деятельность осуществляется как в форме эмпирической оценки единичных объектов (предметов, поступков и т. д.), так и в форме обобщенных оценочных суждений (абстрактные морально-этические нормы - заповеди, кодексы и т. д.).

Для социальной памяти эмоциональная сторона является важным условием, влияющим на мотив запоминания. Не удивительно, что важнейшие содержательные аспекты социальной памяти закрепляются с помощью произведений искусства.

Эмоциональный элемент социальной памяти включает в себя эстетические свойства, чувственные оценки, ощущения, эмоциональный отклик на объекты и происходящие процессы; отношение как результат оценки, выражаемое в более или менее развернутых оценочных суждениях (хорошо/плохо и т. д.).

Объектами оценки могут быть природа, общество, человек и «Я» оценивающего субъекта. Субъектом - индивид, социальная группа, общество в целом. Сложно структурируемая целостность социальной памяти, как видим, обеспечивается множеством разнообразных по природе и содержанию элементов.

На эмоциональную сторону социальной памяти оказывает влияние культурный шок [2]. В масштабе больших групп это то, что известно, в первую очередь, как «социальные потрясения» Причем, чем сильнее испытанные социумом эмоции, тем вероятнее попадание события в предмет социальной памяти. Если событие растянуто во времени, то оно всё равно попадает в социальную память, например, как «золотой век», «монголо-татарское иго», «великая американская депрессия» или «голодомор». Это те стороны, которые касаются непосредственного эмоционального реагирования. В то же время есть в нём и аспекты, связанные с этичностью (собственно, ценностными ориентациями), которая в масштабе большой группы существует как моральный кодекс. В развитых формах больших групп они регулируются или специальными социальными институтами (церковь), или закрепляются в виде более менее прописанных форм (законодательство). Естественно, что они в каждой единичной большой группе опираются на то, что мы обозначили как «народные традиции», в которых выделена эта самая этическая сторона.

Конкретизация на менее масштабные социальные группы связана с единичным наполнением моральных кодексов - ценностные ориентации, принятые на фирме (уровень конгломерата малых групп); неписанные правила и нормы малой группы; иерархия ценностей отдельно взятой семьи (уровень микрогруппы). Также в предмет социальной памяти на этих уровнях по аксиологическому элементу входят воспоминания о приятных и неприятных переживаниях в связи с жизнью соответствующей социальной группы.

Следующим видом памяти рассмотрим тот, который в общей психологии обозначен как словесно-логическая (вербальная) память. Этот вид индивидуальной памяти соответствует когнитивному и информаци- 
онному функциональным элементам, а его теоретической основой является соотнесение объектов. В информационной деятельности активность субъекта, направленная на объект, не модифицирует его, не разрушает и не реконструирует, а отражается субъектом и возвращается к нему в виде знания об этом объекте. Здесь речь идет о развитии исторических процессов во времени, изменчивости и противоречивости их разворачивания; построении перспектив развития общества. В отношении социальной памяти этот вербальный компонент воплощается в текстах исторических книг, устных историях, учебниках, сохраняющих и передающих последующим поколениям исторические знания. В данном случае можно говорить о дискурсе социально-исторической памяти.

На уровне конгломерата малых групп предмет социальной памяти по информационному компоненту представлен знаниями о прошлом фирмы; её миссии, стратегии и другими сведениями, составляющих содержание корпоративной памяти [3].

В малой группе эти представления конкретизируются знанием своей работы, каким образом она вписывается в общую систему.

На уровне микрогруппы на первый план выходят мировоззренческие моменты каждого её члена, вплоть до того, что человек читает, насколько знает историю, насколько способен видеть своё положение в контексте истории.

Оставшийся компонент - коммуникативная деятельность (или общение) в соответствующей теории предполагает направленность на второй субъект. Основу для выделения этого компонента деятельности составляют взаимоотношения субъектов носителей социально-исторической памяти. Прежде всего, речь идет о субъекте, являющимся ответственным за сохранение и передачу содержания исторической памяти (в ее вербальном и эмоциональном синтезе). Другой субъект - партнер в коммуникации по поводу социальной памяти является представителем последующего поколения, которому предстоит перенять содержание памяти для последующей передачи будущим поколениям. По своей сути, социально-историческая память есть продукт и процесс коммуникации. Коммуникация является важнейшим механизмом трансляции социально-исторической памяти.

Коммуникация является не просто действием, а именно взаимодействием, поскольку оно осуществляется между многими, несколькими или, по крайней мере, двумя субъектами, каждый из которых является носителем памяти и допускает ее наличие в своих партнерах. Это означает, что коммуникация является деятельностью субъекта - носителя памяти, направленной на других субъектов - носителей памяти и не превращающей их в объекты, а, напротив - ориентирующейся на них именно как на субъекты, но функционально представленных как партнеры в процессе трансляции памяти.

Продуктом этой деятельности является вовлечение субъекта в дискурс по поводу социальной памяти.

Эффективность коммуникации как дискурсивной деятельности зависит от личностных социальных качеств субъектов, способствующих трансляции памяти: характера, способности, эмоционального мир коммуникантов, способности к сопереживанию, эмпатии, наличии определенного настроя, необходимого для коммуникации по поводу социально-исторической памяти. Важно также наличие адекватного восприятия содержания памяти, творческих способностей, неравнодушного отношения к судьбе страны, народа, другого сообщества, к которому принадлежит человек и с которым идентифицирует себя.

В контексте предмета социальной памяти по этому функциональному элементу можно говорить о социально активной личности, принадлежащей к элите общества. Речь идет об элите в смысле В. Парето [5], который к элите относил людей независимо от социального положения и степени доступа к власти, но обладающих способностью ставить интересы социума выше личных интересов.

На уровне больших групп это, так называемые, исторические личности, обладающие харизмой, оставившие заметный след в жизни страны. Они служат образцом для подражания, и вызывают к себе соответствующее чувство: герои - восхищение, антигерои - презрение и отвращение.

Рассмотрев предмет памяти через функциональные элементы, видим, что эта сто- 
рона социальной памяти является внешней для её субъектов. Что касается внутреннего аспекта, то здесь необходимо сконцентрировать внимание на той процессуальности, которая связана с переводом во внутренний план (интериоризация) и наоборот - извлечение из «внутреннего» хранилища прошлого опыта (экстериоризация). Сочетание этих двух процессов послужило основой теории социального конструирования реальности Бергера и Лукмана. В этом плане возможно рассматривать социальную память как объект социального конструирования.

\section{Литература}

1. Гуссерль Э. Идеи к чистой феноменологии и феноменологической философии. Кн. 1: Общее введение в чистую феноменологию. / Пер. А. В. Михайлов, Н. А. Михай- лова. - М.: Акад. Проект, 2009. - 496 с.

2. Ионин Л. Г. Социология культуры: путь в новое тысячелетие: учебн. пособие для студентов вузов. - 3-е изд., перераб. и доп. - М.: Логос, 2000. - 431 с.

3. Корпоративная память [Электронный ресурс] / Большая Энциклопедия Нефти Газа: портал научно-технической информации ЭБ Нефть и Газ. - Режим доступа: http:/www. ngpedia.ru/id240500p1.html (6.02.2013), свободный. - Загл. с экрана.

4. Познавательные процессы и способности в обучении: учеб. пособие для студентов пед. ин-тов. / В. Д. Шадриков и др.; под ред. В. Д. Шадрикова. - М.: Просвещение, 1990. - 142 с.

5. Теоретическая социология. Антология: в 2 ч. Ч. 1. / Пер. с англ., фр., нем., ит.; сост. и отв. ред. С. П. Баньковская. - М.: Книжный дом «Университет», 2002. — 424 с.

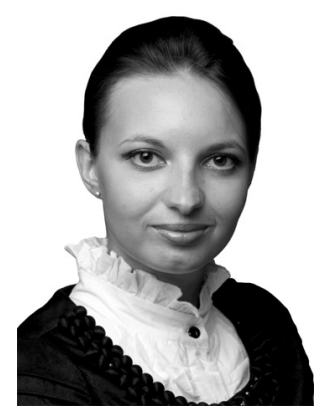

Эллина Геннадьевна Позднякова-Кирбятьева - кандидат социологических наук, докторант кафедры политологии, социологии и культурологии Харьковского национального педагогического университета им. Г. С. Сковороды.

Ellina Gennadyevna Pozdnyakova-Kirbatyeva - Ph.D., Candidate of Sociology, competitor for Doctor's degree at the Kharkov National Pedagogical University of G. S. Skovoroda name department of Political Science, Sociology and Study of Culture.

69124, Украина, г. Запорожье, ул. Курузова, 11А, кв. 82

11 A Kuruzova st., app. 82, 69124, Zaporozhye, Ukraine

Тел.: 38 (063) 316-44-99; e-mail: cobrian@mail.ru 